\title{
Intermetallic Reactions in Reflowed and Aged Sn-58Bi BGA Packages with Au/Ni/Cu Pads
}

\author{
C.C. Chi, L.C. Tsao, C.W. Tsao, and T.H. Chuang
}

\author{
(Submitted February 14, 2006; in revised form March 7, 2007)
}

\begin{abstract}
The reflow of $\mathrm{Sn}-58 \mathrm{Bi}$ solder joints in a BGA package with $\mathrm{Au} / \mathrm{Ni} / \mathrm{Cu}$ pads has been performed by employing various temperature profiles, which results in the formation of $\left(\mathrm{Au}_{0.66} \mathbf{N i}_{0.34}\right)\left(\mathrm{Sn}_{0.82} \mathrm{Bi}_{0.18}\right)_{4}$ intermetallic flakes in the solder matrix. The reflow operation performed at a peak temperature of $180{ }^{\circ} \mathrm{C}$ for a melting time of $80 \mathrm{~s}$ gives a ball shear strength of $9.1 \mathrm{~N}$, which decreases drastically to lower values between 6.4 and 4.6 $\mathrm{N}$ after further aging at temperatures from 75 to $125^{\circ} \mathrm{C}$. Double layers of intermetallic compounds with the compositions of $\left(\mathrm{Au}_{0.30} \mathrm{Ni}_{0.70}\right)\left(\mathrm{Sn}_{0.90} \mathrm{Bi}_{0.10}\right)_{4} / \mathrm{Ni}_{3} \mathrm{Sn}_{4}$ can be found at the solder/pad interfaces of the aged $\mathrm{Sn-58Bi}$ solder joints. Ball shear testing of the reflowed specimens shows ductile fracture through the solder matrix, which changes to brittle cleavage fracture mainly along the $\left(\mathrm{Au}_{0.30}\right.$ $\left.\mathrm{Ni}_{0.70}\right)\left(\mathrm{Sn}_{0.90} \mathrm{Bi}_{0.10}\right)_{4}$ intermetallic layer after aging at various temperatures. The measurement of ball shear strengths $(S)$ reveals a linear relation with the thicknesses $(X)$ of $\left(\mathrm{Au}_{0.30} \mathrm{Ni}_{0.70}\right)\left(\mathrm{Sn}_{0.90} \mathrm{Bi}_{0.10}\right)_{4}$ intermetallic layers: $S=7.13-0.33 X$.
\end{abstract}

Keywords aging, ball shear strength, intermetallics, reflow, Sn-58Bi solder BGA

\section{Introduction}

Eutectic Sn-58wt.\%Bi alloy has been considered a promising $\mathrm{Pb}$-free solder for low-temperature applications. This alloy possesses the merits of low melting point $\left(138^{\circ} \mathrm{C}\right)$, high tensile strength (Ref 1), and good creep resistance (Ref 2, 3). On the other hand, the $\mathrm{Au} / \mathrm{Ni}$ metallization has been one of the most commonly used surface finishes for printed circuit boards (PCB) in electronic packages. The Au thin film provides the beneficial effects of oxidation protection and wetting improvement for $\mathrm{Cu}$ pads, while the Ni layer acts as a diffusion barrier between $\mathrm{Au}$ and $\mathrm{Cu}$. During the reflow process, the Au surface finish dissolves quickly into the solder matrix and a liquid/solid reaction occurs at the interface of $\mathrm{Sn}-58 \mathrm{Bi}$ solder and $\mathrm{Ni}$ layer. The resultant intermetallic formation affects the bonding efficiency of the solder joints. In addition, the aging effect caused by heat generated from operating the electronic devices leads to intermetallic growth, and this has become quite an important issue for the reliability of the packages (Ref 4).

The intermetallic reactions occurred at the interfaces between $\mathrm{Sn}-58 \mathrm{Bi}$ solders and $\mathrm{Ni}$ substrates have been intensively investigated (Ref 5-8). After aging the $\mathrm{Sn}-58 \mathrm{Bi} / \mathrm{Ni}$ solder joints at 85,100 , and $120^{\circ} \mathrm{C}$, Chen et al. reported the formation of $\mathrm{Ni}_{3} \mathrm{Sn}_{4}$ intermetallic compounds at the interfaces, and the growth kinetics of these $\mathrm{Ni}_{3} \mathrm{Sn}_{4}$ intermetallics was analyzed and an activation energy of $90 \mathrm{~kJ} / \mathrm{mol}$ obtained. Chiu et al. (Ref 6) further studied the interfacial reactions between

C.C. Chi, L.C. Tsao, C.W. Tsao, and T.H. Chuang, Institute of Materials Science and Engineering, National Taiwan University, Taipei 106, Taiwan. Contact e-mail: tunghan@ntu.edu.tw.
$\mathrm{Sn}-58 \mathrm{Bi}$ solders and $\mathrm{Ni}$ substrates at temperatures ranging from 200 to $400{ }^{\circ} \mathrm{C}$. They found a $\mathrm{Ni}_{3}\left(\mathrm{Sn}_{0.99} \mathrm{Bi}_{0.01}\right)_{4}$ intermetallic phase with the composition of $\mathrm{Ni}_{41.5} \mathrm{Sn}_{57.9} \mathrm{Bi}_{0.6}$ formed at the interface, and the intermetallic growth was diffusion-controlled with an activation energy of $28.3 \mathrm{~kJ} / \mathrm{mol}$. Kang et al. (Ref 7) also investigated the intermetallic reaction of a liquid $\mathrm{Sn}-58 \mathrm{Bi}$ solder with $\mathrm{Ni}(0.5-2.0 \mu \mathrm{m}) / \mathrm{Cu}(4 \mu \mathrm{m}) / \mathrm{Si}$ substrate and reported the appearance of $\mathrm{Ni}_{3} \mathrm{Sn}_{4}$ intermetallic compounds at the $\mathrm{Sn}-58 \mathrm{Bi} / \mathrm{Ni}$ interface. The growth kinetics of such an interfacial intermetallic was also diffusion-controlled. Young et al. (Ref 8) used electro- and electroless-plated $\mathrm{Ni}$ on $\mathrm{Cu}$ plates to react with $\mathrm{Sn}-58 \mathrm{Bi}$ solder at 145 and $185{ }^{\circ} \mathrm{C}$. They found that by increasing the phosphorus content, the electroless-plated $\mathrm{Ni}$ could act as a good reaction barrier between $\mathrm{Sn}-58 \mathrm{Bi}$ solder and $\mathrm{Cu}$ substrate. As the soldering temperature rose, the growth of $\mathrm{Ni}_{3} \mathrm{Sn}_{4}$ intermetallic compound was accelerated, which allowed the $\mathrm{Cu}$ atoms to join in the reaction. In this case, the morphology of the $\mathrm{Sn}-58 \mathrm{Bi} / \mathrm{Ni}$ interface would change from faceting to a saw-tooth type.

In a reflowed $\mathrm{Sn}-37 \mathrm{~Pb}$ solder BGA package with $\mathrm{Au} / \mathrm{Ni}$ surface finish, the dissolved $\mathrm{Au}$ atoms were found to form flake-shaped $\mathrm{AuSn}_{4}$ intermetallics in the solder matrix, and further aging of the reflowed specimen caused the $\mathrm{AuSn}_{4}$ intermetallic phase to migrate from the solder matrix to the Sn$37 \mathrm{~Pb}$ solder/ $\mathrm{Ni}$ layer interface (Ref 9). According to the explanation of Ho et al., it has been the Ni layer that attracts $\mathrm{AuSn}_{4}$ intermetallics and causes their migration to the $\mathrm{Ni} / \mathrm{Cu}$ pads (Ref 10). However, the behavior of $\mathrm{AuSn}_{4}$ intermetallics in a $\mathrm{Sn}-3.5 \mathrm{Ag}$ solder BGA package with $\mathrm{Au} / \mathrm{Ni} / \mathrm{Cu}$ pads could be quite different. In this case, the $\mathrm{AuSn}_{4}$ intermetallic flakes after aging would continue to remain in the solder matrix. The discrepancy might be attributed to the peening effect of $\mathrm{Ag}_{3} \mathrm{Sn}$ precipitates in the $\mathrm{Sn}-3.5 \mathrm{Ag}$ solder matrix on the $\mathrm{AuSn}_{4}$ intermetallic flakes (Ref 11).

In this present study, the morphology and compositions of various intermetallic phases formed in a Sn-58Bi BGA package with $\mathrm{Au} / \mathrm{Ni}$ surface finish after reflow and aging processes are 
identified. The growth kinetics of intermetallics formed at solder/pad interfaces are analyzed. Finally, the bonding strengths of the solder joints are measured via ball shear testing.

\section{Experimental}

The Sn-58Bi solder BGA package used in this study contained a Si dummy die on a resin substrate, encapsulated with molding compound. Each substrate was fitted with 49 $(7 \times 7) \mathrm{Cu}$ pads which were electroplated with $5 \mu \mathrm{m}$ thick $\mathrm{Ni}$, and immersion coated with $0.5 \mu \mathrm{m}$ thick Au. The eutectic point $\left(T_{\mathrm{e}}\right)$ of $\mathrm{Sn}-58 \mathrm{Bi}$ as measured by a differential scanning calorimeter (DSC) was $138^{\circ} \mathrm{C}$. The Sn-58Bi (wt.\%) solder balls of $0.4 \mathrm{~mm}$ in diameter were dipped in rosin mildly activated (RMA) flux, placed on the $\mathrm{Au} / \mathrm{Ni}$ surface finished $\mathrm{Cu}$ pads, and then reflowed in a hot-air furnace. The reflow furnace was installed with five heating zones. Temperature profiles with various peak temperatures $\left(T_{\max }\right)$ and melting times $\left(\Delta t_{\mathrm{m}}\right.$, $T>T_{\mathrm{e}}$ ) as shown in Fig. 1 were employed for the soldering process. In addition, a certain number of specimens after reflow at a peak temperature $180{ }^{\circ} \mathrm{C}$ for a melting time of $80 \mathrm{~s}$ were

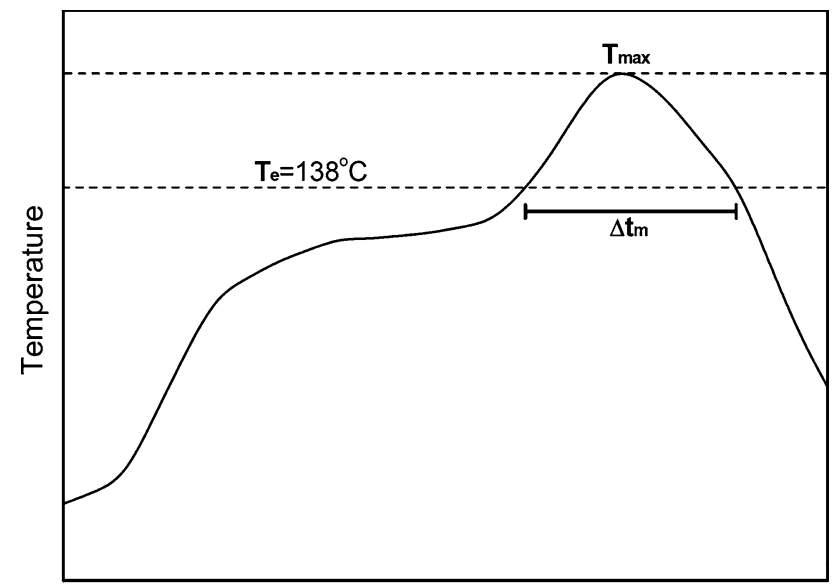

Reflow Time

Fig. 1 Temperature profile for the reflow process of Sn-58Bi solder BGA package in this study $\left(T_{\max }=\right.$ peak temperature, $\Delta t_{\mathrm{m}}=$ melting time for $T>T_{\mathrm{e}}, T_{\mathrm{e}}$ : eutectic point)

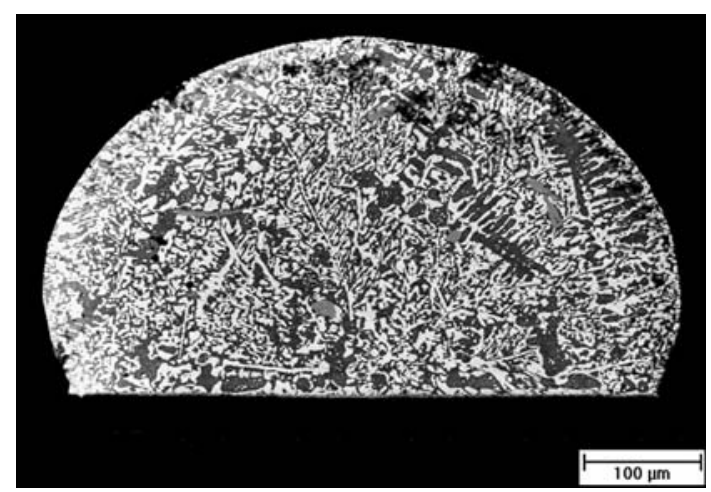

Fig. 2 Typical morphology of a solder ball in Sn-58Bi BGA package after reflow further aged at $75,100,115$, and $125^{\circ} \mathrm{C}$ for various times ranging from 100 to $1000 \mathrm{~h}$.

The reflowed and aged Sn-58Bi BGA packages were crosssectioned through a row of solder balls, ground with 2000 grit $\mathrm{SiC}$ paper and polished with $0.3 \mu \mathrm{m} \mathrm{Al}_{2} \mathrm{O}_{3}$ powder. The microstructure of solder joints was observed using a scanning electron microscope (SEM). The chemical compositions of
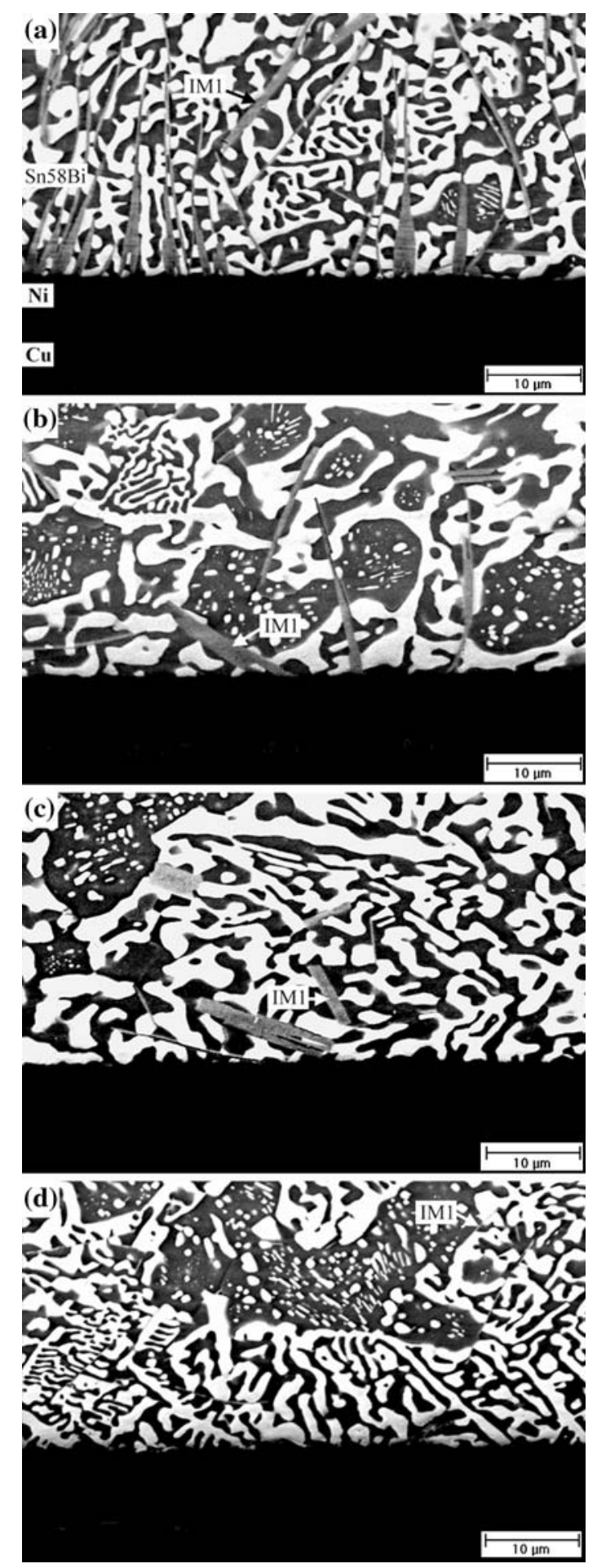

Fig. 3 Microstructure of the Sn-58Bi solder joints reflowed at various peak temperatures for a melting time of $60 \mathrm{~s}$ : (a) $160{ }^{\circ} \mathrm{C}$, (b) $170{ }^{\circ} \mathrm{C}$, (c) $180{ }^{\circ} \mathrm{C}$, and (d) $190{ }^{\circ} \mathrm{C}$ 


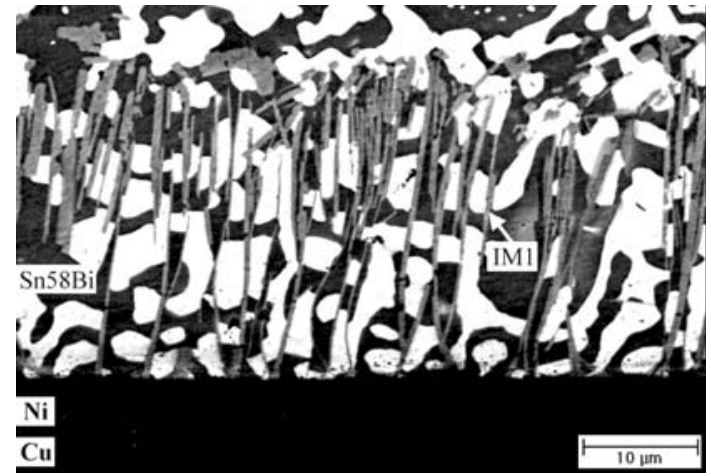

Fig. 4 Intermetallic flakes IM1 tend to form at a distance away from the solder/pad interface after reflowing at $160{ }^{\circ} \mathrm{C}$ for a longer melting time of $80 \mathrm{~s}$

various intermetallic phases were analyzed via an energy dispersive $\mathrm{x}$-ray spectrometer (EDX) installed in the SEM. The bonding strengths of the solder joints were measured by ball shear tests, for which the shear rate and shear height were set at $0.1 \mathrm{~mm} / \mathrm{s}$ and $80 \mu \mathrm{m}$, respectively.

\section{Results and Discussion}

The typical morphology of Sn-58Bi solder balls reflowed on $\mathrm{Au} / \mathrm{Ni} / \mathrm{Cu}$ pads in BGA packages is shown in Fig. 2. The solder ball contains a eutectic lamellar microstructure of pure Bi phase (in white) and $\beta$-Sn solid solution (in black). In addition, some flake-shaped intermetallics in the color of gray appear in the solder matrix. EDX analysis indicates that the chemical composition (at.\%) of these gray intermetallic flakes is $\mathrm{Au}: \mathrm{Ni}: \mathrm{Sn}: \mathrm{Bi}=13.05: 6.84: 65.63: 14.48$, which corresponds to the $\left(\mathrm{Au}_{0.66} \mathrm{Ni}_{0.34}\right)\left(\mathrm{Sn}_{0.82} \mathrm{Bi}_{0.18}\right)_{4}$ phase (IM1). Metallographic observations of a higher magnification in Fig. 3 reveal that the distribution of these flake-shaped IM1 intermetallic compounds is dependent on the reflow conditions. On the reflow profile having lower peak temperatures $\left(T_{\max }\right)$, the $\left(\mathrm{Au}_{0.66-}\right.$ $\left.\mathrm{Ni}_{0.34}\right)\left(\mathrm{Sn}_{0.82} \mathrm{Bi}_{0.18}\right)_{4}$ intermetallic flakes tend to position vertically at the solder/pad interface (Fig. 3a). However, the increase in the peak temperature causes them to form in the solder matrix (Fig. 3b-d). These intermetallic flakes also tend to appear at a distance away from the solder/pad interface on the reflow profile having longer melting time (Fig. 4 and 5). In this case, they will either stay in the interior of the solder matrix or move farther to the outer surface of the solder ball (Fig. 5). Together with the migration of intermetallic compounds, the intermetallic flakes also coarsen into thicker plates (Fig. 5) or even cubic blocks (Fig. 5). It has been mentioned that the Au thin film on $\mathrm{Au} / \mathrm{Ni} / \mathrm{Cu}$ pads dissolves quickly at the onset of the reflow process. Subsequently, the exposed Ni layer will also dissolve into the liquid solder. However, the dissolution rate of $\mathrm{Ni}$ is much slower than that of the Au film (Ref 12). The dissolved $\mathrm{Au}$ and $\mathrm{Ni}$ atoms in liquid $\mathrm{Sn}-58 \mathrm{Bi}$ solder react predominantly with the $\mathrm{Sn}$ element to form $\left(\mathrm{Au}_{0.66-}\right.$ $\left.\mathrm{Ni}_{0.34}\right)\left(\mathrm{Sn}_{0.82} \mathrm{Bi}_{0.18}\right)_{4}$ intermetallic flakes (IM1) in between the Bi lamellae. The increase in peak temperature $\left(T_{\max }\right)$ or melting time $\left(\Delta t_{\mathrm{m}}\right)$ of the reflow profile causes these $\mathrm{Au}$ and $\mathrm{Ni}$ atoms to diffuse to greater distances and precipitate farther away from
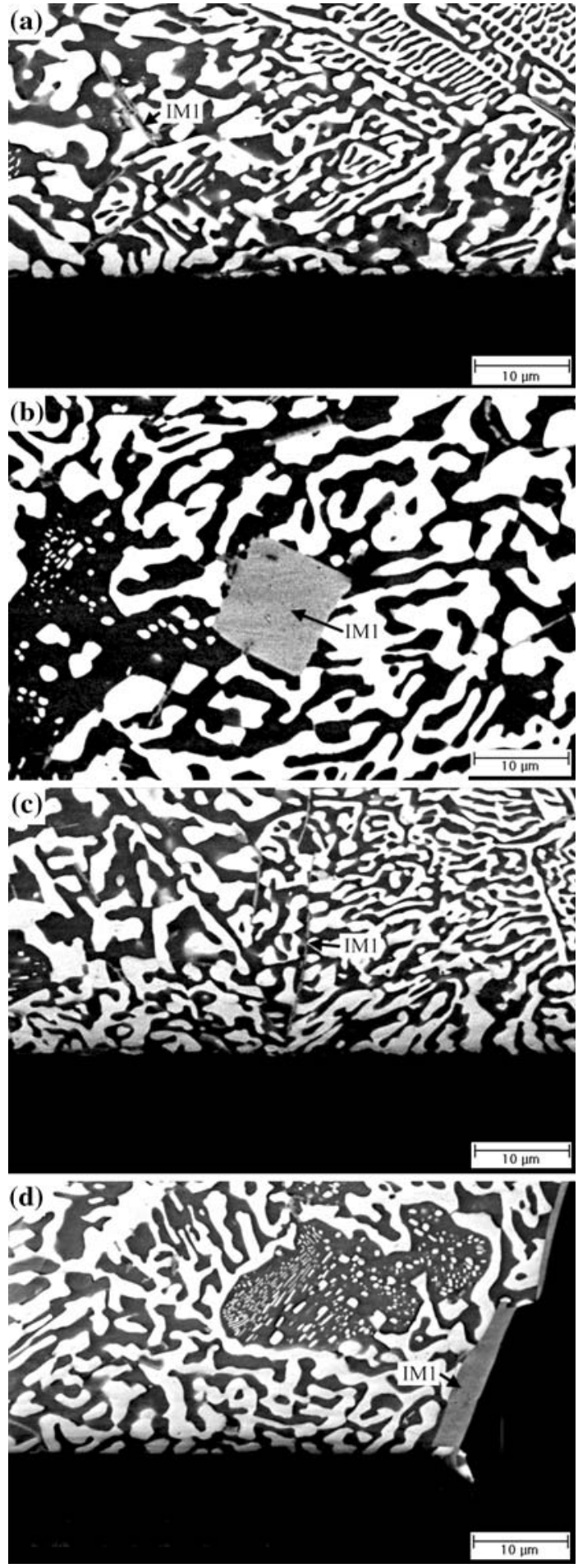

Fig. 5 Microstructure of the $\mathrm{Sn}-58 \mathrm{Bi}$ solder joints reflowed at the peak temperatures of $160{ }^{\circ} \mathrm{C}(\mathrm{a}, \mathrm{b})$ and $190{ }^{\circ} \mathrm{C}(\mathrm{c}, \mathrm{d})$ for a longer melting time of $140 \mathrm{~s}$

the solder/pad interface. It is the surface tension that causes them to coarsen into thicker plates or cubic blocks.

The specimens reflowed at the peak temperature of $180{ }^{\circ} \mathrm{C}$ for the melting time of $80 \mathrm{~s}$ have been further aged at temperatures ranging from 75 to $125^{\circ} \mathrm{C}$ for various times from 100 to $700 \mathrm{~h}$. It can be seen in Fig. 6 and 7 that a gray layer of intermetallic phase (IM2) appears at the solder/pad interface, 

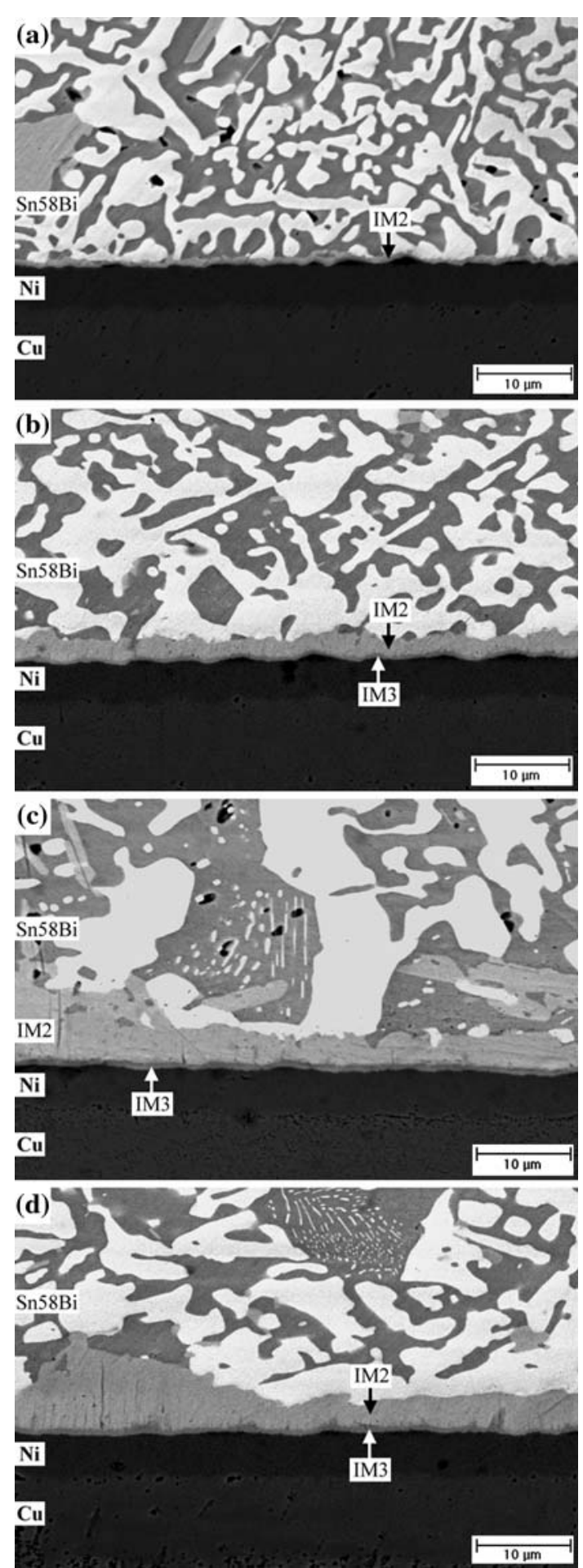

Fig. 6 Microstructure of the Sn-58Bi solder joints after aging at various temperatures for $100 \mathrm{~h}$ : (a) $75^{\circ} \mathrm{C}$, (b) $100{ }^{\circ} \mathrm{C}$, (c) $115^{\circ} \mathrm{C}$, and (d) $125^{\circ} \mathrm{C}$

which grows with the increase of aging temperature and aging time. The chemical compositions of IM2 intermetallic compounds formed in the Sn-58Bi solder joints after aging under various conditions are listed in Table 1 . As such a gray interfacial intermetallic phase (IM2) grows, another thin intermetallic phase (IM3, in dark color) forms between IM2 layer and $\mathrm{Ni} / \mathrm{Cu}$ pad. EDX analysis indicates that the gray and
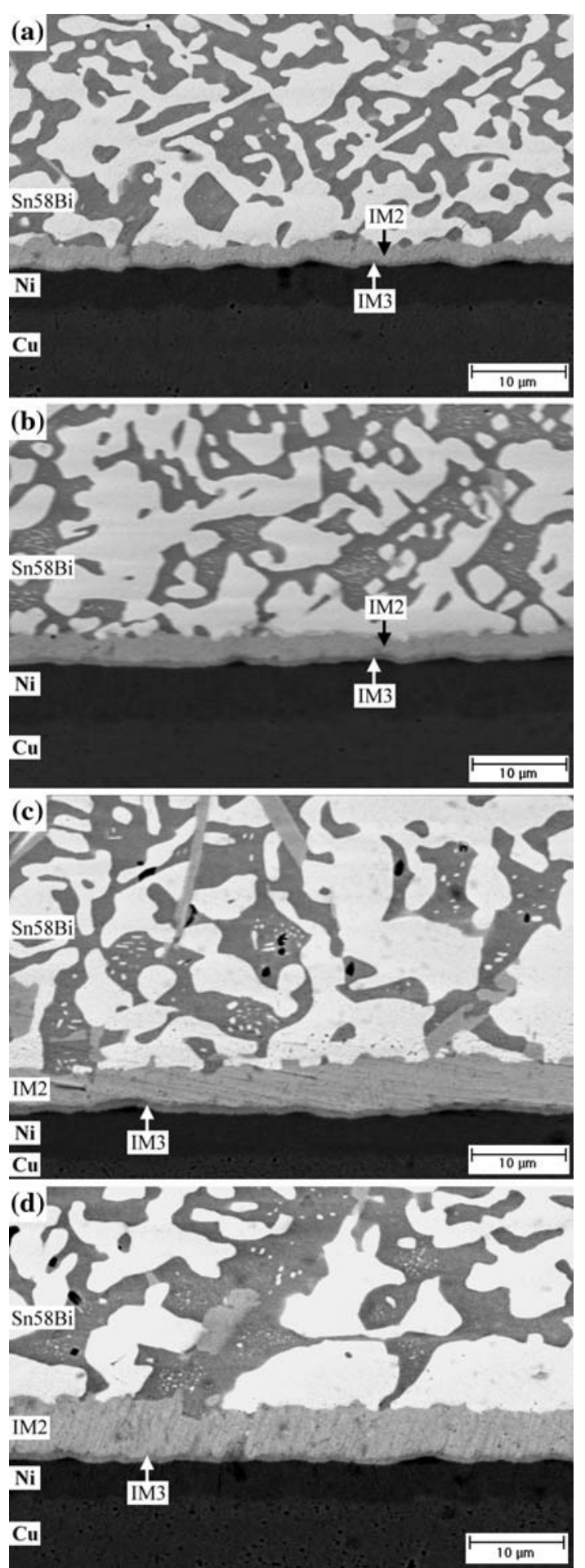

Fig. 7 Microstructure of the Sn-58Bi solder joints after aging at $100{ }^{\circ} \mathrm{C}$ for various times: (a) $100 \mathrm{~h}$, (b) $300 \mathrm{~h}$, (c) $500 \mathrm{~h}$, and (d) $700 \mathrm{~h}$

dark intermetallic layers possess compositions of $\left(\mathrm{Au}_{0.30}\right.$ $\left.\mathrm{Ni}_{0.70}\right)\left(\mathrm{Sn}_{0.90} \mathrm{Bi}_{0.10}\right)_{4}$ and $\mathrm{Ni}_{3} \mathrm{Sn}_{4}$, respectively. It is evident that the $\left(\mathrm{Au}_{0.66} \mathrm{Ni}_{0.34}\right)\left(\mathrm{Sn}_{0.82} \mathrm{Bi}_{0.18}\right)_{4}$ intermetallic flakes (IM1) in the solder matrix have migrated to the solder/pad interface, which is similar to the case reported for a $\mathrm{Sn} 37 \mathrm{~Pb}$ BGA package by Minor and Morris (Ref 9). From Table 1, in which the compositions of IM1 and IM3 are also included for 
comparison, the interfacial intermetallic phase IM2 has higher $\mathrm{Ni}$ and $\mathrm{Sn}$ contents than the IM1 flakes in the solder matrix. It implies that the $\left(\mathrm{Au}_{0.66} \mathrm{Ni}_{0.34}\right)\left(\mathrm{Sn}_{0.82} \mathrm{Bi}_{0.18}\right)_{4}$ intermetallics (IM1) migrated toward the Ni layers on $\mathrm{Cu}$ pads have reacted simultaneously with the $\mathrm{Ni}$ atoms, causing its composition to change to $\left(\mathrm{Au}_{0.30} \mathrm{Ni}_{0.70}\right)\left(\mathrm{Sn}_{0.90} \mathrm{Bi}_{0.10}\right)_{4}$. Further increasing the aging time and temperature, the $\mathrm{Sn}$ atoms in the $\mathrm{Sn}-58 \mathrm{Bi}$ solder
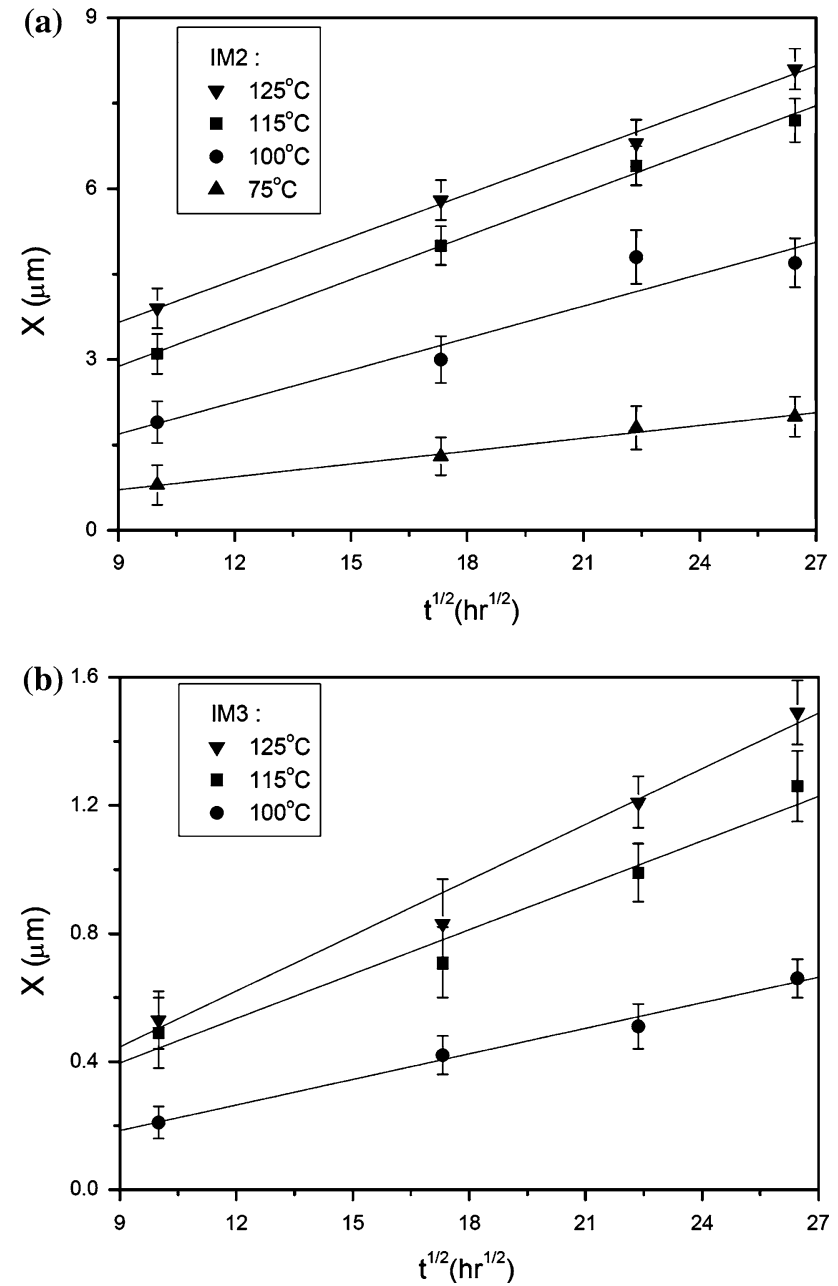

Fig. 8 Thickness $(X)$ of the intermetallic layers formed at the solder/pad interfaces of Sn-58Bi BGA packages after aging at various temperatures versus the square root of time $\left(t^{1 / 2}\right)$ : (a) IM2 $\left(\mathrm{Au}_{0.30-}\right.$ $\left.\mathrm{Ni}_{0.70}\right)\left(\mathrm{Sn}_{0.90} \mathrm{Bi}_{0.10}\right)_{4}$ and (b) IM3 $\mathrm{Ni}_{3} \mathrm{Sn}_{4}$ matrix have diffused through the IM2 intermetallic layer to react with the $\mathrm{Ni}$ layer on $\mathrm{Cu}$ pads to form the $\mathrm{Ni}_{3} \mathrm{Sn}_{4}$ phase (IM3).

The growth thicknesses $(X)$ of IM2 and IM3 intermetallic layers formed at the solder/pad interfaces after aging at various temperatures are measured and presented as a function of the square root of aging time $\left(t^{1 / 2}\right)$ in Fig. 8. All plots show a linear relation, which indicate that the growth kinetics for both IM2 and IM3 intermetallic compounds is diffusion-controlled. The growth rate constants $\left(K=X / t^{1 / 2}\right)$ of both intermetallic layers are also calculated from Fig. 8 and plotted in an Arrhenius diagram in Fig. 9. The slopes of both curves give the activation energies $(Q)$ for the growth of IM2 and IM3 intermetallic compounds, which are 58.06 and $80.28 \mathrm{~kJ} / \mathrm{mol}$, respectively. Yeh and Huntington (Ref 13) reported that the activation energy for the lattice diffusion of Ni atoms in $\mathrm{Sn}$ is $54.2 \mathrm{~kJ} / \mathrm{mol}$. This value is quite consistent with the activation energy for the growth of IM2 intermetallics, which confirms the above inference that the diffusion of $\mathrm{Ni}$ atoms through the $\left(\mathrm{Au}_{0.66} \mathrm{Ni}_{0.34}\right)\left(\mathrm{Sn}_{0.82} \mathrm{Bi}_{0.18}\right)_{4}$ phase causes the change of its composition to $\left(\mathrm{Au}_{0.30} \mathrm{Ni}_{0.70}\right)\left(\mathrm{Sn}_{0.90} \mathrm{Bi}_{0.10}\right)_{4}$. On the other hand, the activation energy for the self-diffusion of $\mathrm{Sn}$ as measured by Lange and Hassner (Ref 14) is $93.8 \mathrm{~kJ} / \mathrm{mol}$, which is near the value for the intermetallic growth of the IM3 phase. It is also verified that the growth rate of $\mathrm{Ni}_{3} \mathrm{Sn}_{4}$ intermetallic layer (IM3)

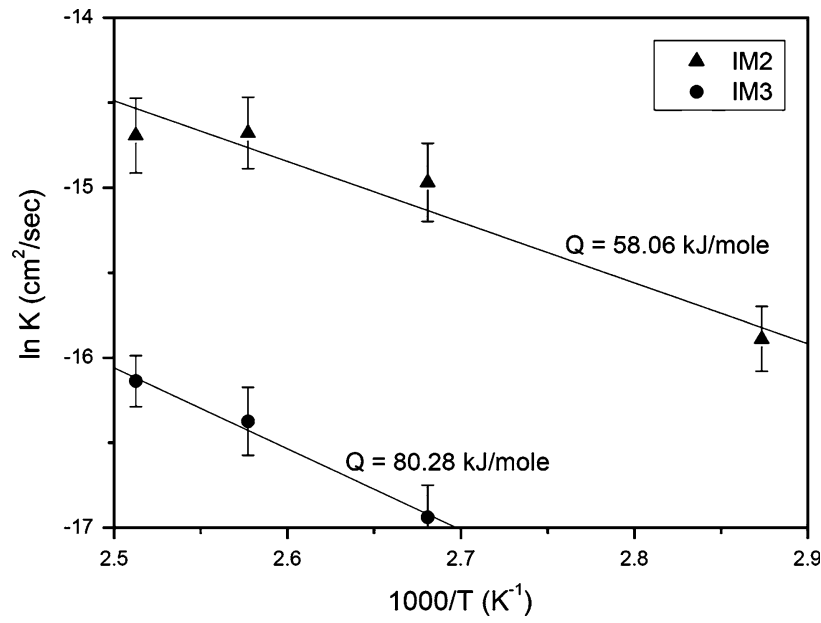

Fig. 9 Arrhenius plot of the reaction constants $(K)$ for the growth of intermetallic layers formed at the solder/pad interface of Sn-58Bi BGA packages after the aging processes: IM2 $\left(\mathrm{Au}_{0.30-}\right.$ $\left.\mathrm{Ni}_{0.70}\right)\left(\mathrm{Sn}_{0.90} \mathrm{Bi}_{0.10}\right)_{4} ; \mathrm{IM} 3 \mathrm{Ni}_{3} \mathrm{Sn}_{4}$

Table 1 Chemical Compositions (at.\%) of Intermetallic Compounds Formed in Sn-58Bi Solder Joints After the Reflow and Aging Processes

\begin{tabular}{|c|c|c|c|c|c|c|}
\hline \multirow{2}{*}{$\begin{array}{l}\text { IMC } \\
\text { Process }\end{array}$} & \multirow{2}{*}{$\begin{array}{c}\text { IM1 } \\
\text { Reflow }\end{array}$} & \multicolumn{4}{|c|}{ IM2 } & \multirow{2}{*}{$\begin{array}{c}\text { IM3 } \\
\text { Aging }\end{array}$} \\
\hline & & Aging $115^{\circ} \mathrm{C}, 100 \mathrm{~h}$ & Aging $115^{\circ} \mathrm{C}, 300 \mathrm{~h}$ & Aging $125^{\circ} \mathrm{C}, 100 \mathrm{~h}$ & Aging $125^{\circ} \mathrm{C}, 300 \mathrm{~h}$ & \\
\hline $\mathrm{Au}$ & 13.05 & 7.45 & 6.21 & 4.34 & 5.75 & 0 \\
\hline $\mathrm{Ni}$ & 6.84 & 10.61 & 15.58 & 15.39 & 13.64 & 42.89 \\
\hline $\mathrm{Sn}$ & 65.63 & 73.36 & 70.61 & 73.47 & 72.71 & 57.11 \\
\hline $\mathrm{Bi}$ & 14.48 & 8.58 & 7.60 & 6.80 & 7.89 & 0 \\
\hline
\end{tabular}

IM1: $\left(\mathrm{Au}_{0.66} \mathrm{Ni}_{0.34}\right)\left(\mathrm{Sn}_{0.82} \mathrm{Bi}_{0.18}\right)_{4}$ gray intermetallic flakes in the solder matrix after reflowing; IM2: $\left(\mathrm{Au}_{0.30} \mathrm{Ni}_{0.70}\right)\left(\mathrm{Sn}_{0.90} \mathrm{Bi}_{0.10}\right)_{4}$ gray intermetallic layer in the solder/pad interface after aging; IM3: $\mathrm{Ni}_{3} \mathrm{Sn}_{4}$ dark intermetallic layer in the solder/pad interface after aging 


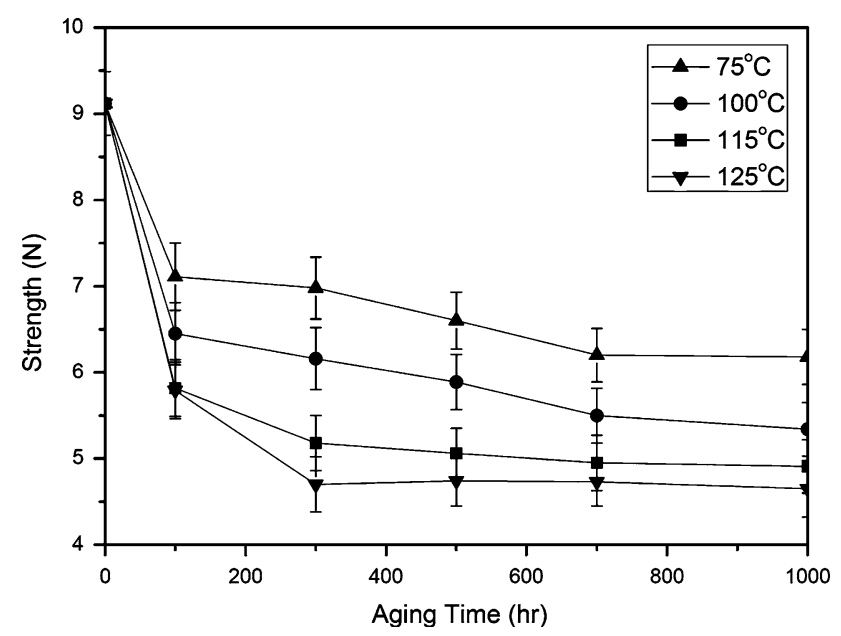

Fig. 10 Ball shear strength of the Sn-58Bi solder joints after aging at various temperatures from 75 to $125{ }^{\circ} \mathrm{C}$ (reflow condition: $T_{\max }=$ $180{ }^{\circ} \mathrm{C}, \Delta t_{\mathrm{m}}=80 \mathrm{~s}$ )
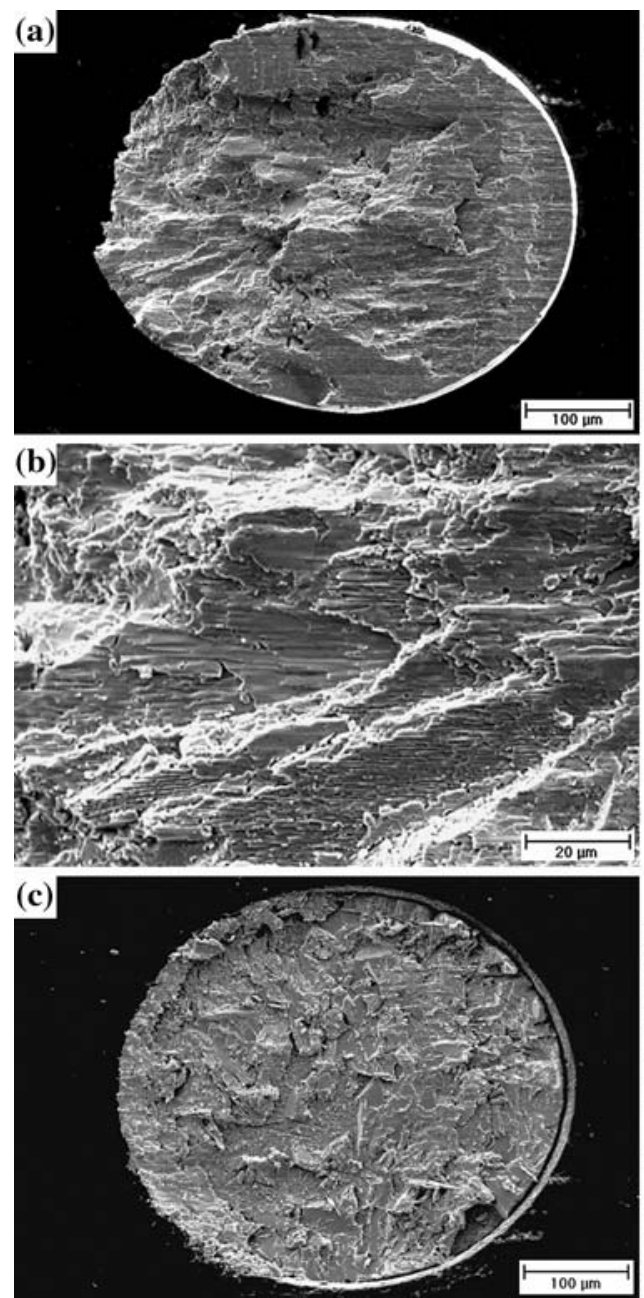

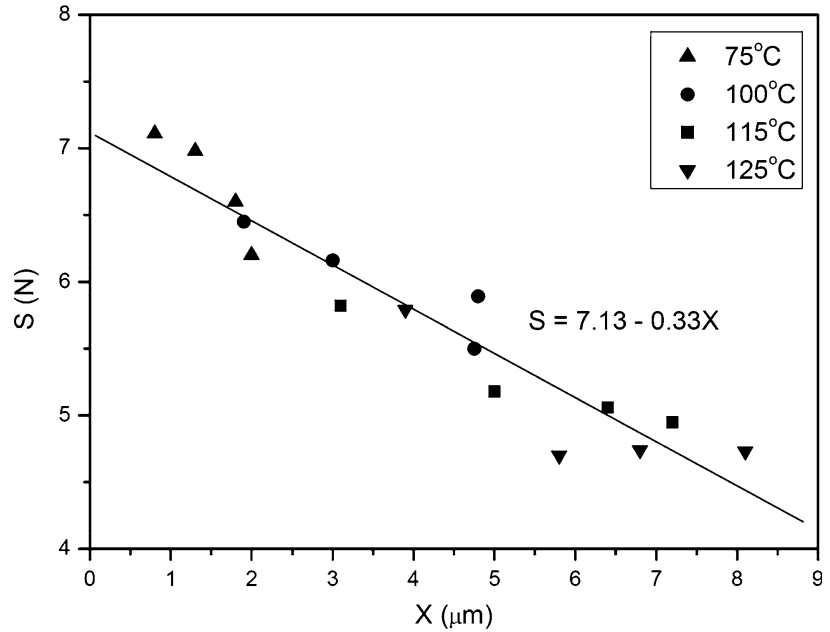

Fig. 11 Ball shear strengths $(S)$ of the Sn-58Bi solder joints as a function of IM2 thicknesses $(X)$ after various aging times and temperatures
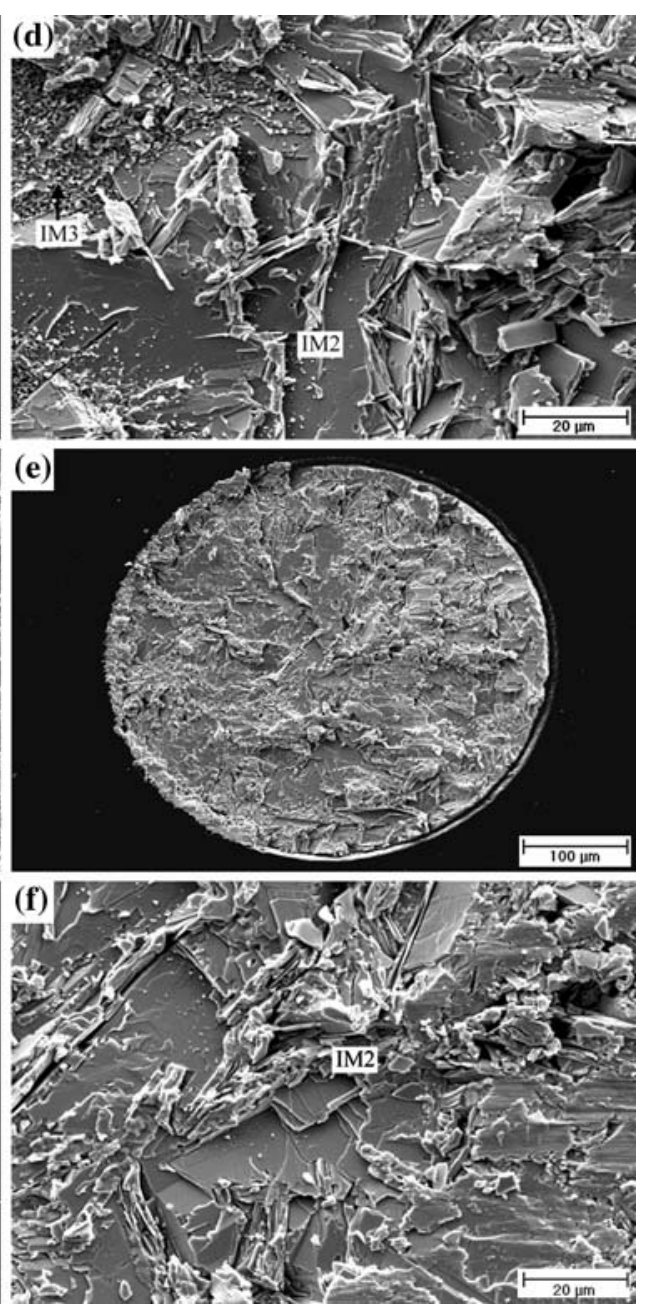

Fig. 12 Typical fractrography of the aged Sn-58Bi solder joints after ball shear tests: (a, b) as reflow; (c, d) $115^{\circ} \mathrm{C}, 100 \mathrm{~h}$; and $(\mathrm{e}, \mathrm{f}) 115{ }^{\circ} \mathrm{C}$, $300 \mathrm{~h}$

is determined by the diffusion of $\mathrm{Sn}$ atoms from $\mathrm{Sn}-58 \mathrm{Bi}$ solder through the IM2 phase containing more than 70 at.\% Sn as indicated in Table 1. Ball shear strengths of the Sn-58Bi solder joints after the aging processes are measured and demonstrated in Fig. 10. It can be seen that the bonding strength of the reflowed specimen $\left(T_{\max }=180{ }^{\circ} \mathrm{C}, \Delta t_{\mathrm{m}}=80 \mathrm{~s}\right)$ is $9.1 \mathrm{~N}$, 
which is higher than the value of a traditional $\mathrm{Sn} 37 \mathrm{~Pb}$ package $(8.7 \mathrm{~N})$ reflowed under the optimized condition $\left(T_{\max }=225^{\circ}\right.$ $\left.\mathrm{C}, \Delta t_{\mathrm{m}}=60 \mathrm{~s}\right) \quad(\operatorname{Ref} 15)$. The ball shear strength drops drastically to values between 7.1 and $5.8 \mathrm{~N}$ after aging at temperatures between 75 and $125^{\circ} \mathrm{C}$ for $100 \mathrm{~h}$. Longer aging times (over $700 \mathrm{~h}$ ) cause the ball shear strengths to decrease further to values between 6.4 and $4.6 \mathrm{~N}$. In order to clarify the cause for the degradation of solder joints, the ball shear strengths $(S)$ of $\mathrm{Sn}-58 \mathrm{Bi}$ BGA packages after aging at various temperatures and times are plotted versus the thickness $(X)$ of IM2 intermetallic layers at the solder/pad interfaces. Figure 11 shows that a linear relation exists in this case: $S=7.13-0.33 X$. It implies that the growth of IM2 intermetallic compounds leads to the embrittlement of interfaces between Sn-58Bi solder balls and $\mathrm{Au} / \mathrm{Ni} / \mathrm{Cu}$ pads. This result can be reconfirmed from the fractography of the aged Sn-58Bi solder joints after ball shear tests as shown in Fig. 12. It reveals that the fracture occurs to the reflowed Sn-58Bi BGA package through the solder ball with ductile dimple characteristics (Fig. 12a, b). On the contrary, the aged specimens show brittle fracture after ball shear tests. Most areas on the fracture surface of aged specimens contain cleavage planes (Fig. 12c-f). EDX analysis indicates that the composition is $\left(\mathrm{Au}_{0.30} \mathrm{Ni}_{0.70}\right)\left(\mathrm{Sn}_{0.90} \mathrm{Bi}_{0.10}\right)_{4}$ for those fracture zones with cleavage, which corresponds to the interfacial IM2 intermetallic phase. However, many fine particles are also found in certain regions (the upper left region, see fractrography in Fig. 12d), which possess a composition of the IM3 phase $\left(\mathrm{Ni}_{3} \mathrm{Sn}_{4}\right)$. The results indicate that the aged Sn$58 \mathrm{Bi}$ solder joints fracture mainly along the IM2 intermetallic layer. The fact that there are less fracture paths along the IM3 layer than along the IM2 layer, implies that the latter is much more brittle than the former.

\section{Conclusions}

Sn-58Bi solder BGA packages with $\mathrm{Au} / \mathrm{Ni} / \mathrm{Cu}$ pads are reflowed at a peak temperatures of $180{ }^{\circ} \mathrm{C}$ for a melting time of $80 \mathrm{~s}$ results in a ball shear strength of $9.1 \mathrm{~N}$. Fractography after ball shear testing reveals ductile fracture through the solder ball. After the reflow processes, a small number of flake-shaped $\left(\mathrm{Au}_{0.66} \mathrm{Ni}_{0.34}\right)\left(\mathrm{Sn}_{0.82} \mathrm{Bi}_{0.18}\right)_{4}$ intermetallic compounds (IM1) appear in the solder matrix. Further aging at temperatures between 75 and $125^{\circ} \mathrm{C}$ leads to the migration of IM1 intermetallic flakes from the solder matrix to the solder/pad interface, as well as the change of its composition to the $\left(\mathrm{Au}_{0.30} \mathrm{Ni}_{0.70}\right)\left(\mathrm{Sn}_{0.90} \mathrm{Bi}_{0.10}\right)_{4}$ phase (IM2). As the aging time increases, an additional intermetallic phase (IM3) with the composition of $\mathrm{Ni}_{3} \mathrm{Sn}_{4}$ begins to form at the interface between IM2 and $\mathrm{Ni}$ layer on the $\mathrm{Cu}$ pad. Aging processes cause the bonding strength of the reflowed specimen to drop drastically from $9.1 \mathrm{~N}$ to lower values between 6.4 and $4.6 \mathrm{~N}$. A linear relation between ball shear strengths $(S)$ and IM2 thicknesses
( $X$ ) has been obtained: $S=7.13-0.33 X$, which implies that the degradation of $\mathrm{Sn}-58 \mathrm{Bi}$ solder joints in this case attributed to the embrittlement of interface caused by the growth of IM2 intermetallic compounds. Fractography of the aged solder joints after ball shear tests reveals brittle cleavage fracture mainly along the IM2 intermetallic layer.

\section{Acknowledgment}

Sincere thanks go to National Science Council, Taiwan, for sponsoring this research under Grant No. NSC-93-2216-E002-024.

\section{References}

1. W.J. Tomlinson and I. Collier, Mechanical Properties and Microstructures of Copper and Brass Joints Soldered with Eutectic Tin-Bismuth Solder, J. Mater. Sci., 1987, 22(5), p 1835-1839

2. Z. Mei and J.W. Morris Jr., Characterization of Eutectic Sn-Bi Solder Joints, J. Electron. Mater, 1992, 21(6), p 599-607

3. C.H. Raeder, L.E. Felton, V.A. Tanzi, and D.B. Knorr, The Effect of Aging on Microstructure, Room-Temperature Deformation, and Fracture of Sn-Bi/Cu Solder Joints, J. Electron. Mater, 1994, 23(7), p 611-617

4. T.H. Chuang, S.Y. Chang, M.D. Cheng, and S.S. Wang, Challenges for the Application of Lead-Free Solders on Ball Grid Array Packages, Bull. College Eng. N.T.U., 2003, 89, p 101-110

5. C. Chen, C.E. Ho, A.H. Lin, G.L. Luo, and C.R. Kao, Long-Term Aging Study on the Solid-State Reaction Between 58Bi42Sn Solder and Ni Substrate, J. Electron. Mater., 2000, 29(10), p 1200-1206

6. M.Y. Chiu, S.Y. Chang, Y.H. Tseng, Y.C. Chan, and T.H. Chuang, Characterization of Intermetallic Compounds Formed During the Interfacial Reactions of Liquid $\mathrm{Sn}$ and $\mathrm{Sn}-58 \mathrm{Bi}$ Solders with $\mathrm{Ni}$ Substrates, Zeitschrift fuer Metallkunde/Mater. Res. Adv. Tech., 2002, 93(3), p 248-252

7. S.K. Kang, R.S. Rai, and S. Purushothaman, Interfacial Reactions During Soldering with Lead-Tin Eutectic and Lead $(\mathrm{Pb})$-Free Tin-Rich Solders, J. Electron. Mater, 1996, 25(7), p 1113-1120

8. B.L. Young and J.G. Duh, Interfacial Reaction and Microstructural Evolution for Electroplated Ni and Electroless Ni in the Under Bump Metallurgy with 42Sn58Bi Solder During Annealing, J. Electron. Mater, 2001, 30(7), p 878-884

9. A.M. Minor and J.W. Morris Jr., Inhibiting Growth of the Au0.5Ni0.5Sn4 Intermetallic Layer in Pb-Sn Solder Joints Reflowed on Au/Ni Metallization, J. Electron. Mater, 2000, 29(10), p 1170-1174

10. C.E. Ho, Y.M. Chen, and C.R. Kao, Reaction Kinetics of Solder-Balls with Pads in BGA Packages During Reflow Soldering, J. Electron. Mater., 1999, 28(11), p 1231-1237

11. C.C. Chi and T.H. Chuang, Intermetallic Reactions in Sn-3.5Ag Solder Ball Grid Array Packages with $\mathrm{Ag} / \mathrm{Cu}$ and $\mathrm{Au} / \mathrm{Ni} / \mathrm{Cu}$ Pads, J. Electron. Mater, in press

12. B. Meagher, D. Schwarz, and M. Ohring, Compound Growth in Platinum/Tin-Lead Solder Diffusion Couples, J. Mater. Sci., 1996, 31(20), p 5479-5486

13. D.C. Yeh, Extreme Fast-Diffusion System: Nickel in Single-Crystal Tin, H.B. Phys. Rev. Lett., 1984, 53(15), p 1469-1472

14. W. Lange and A. Hassner, Messung der Volumenselbstdiffusion im polykristallinen Zinn, Phys. Stat. Solidi., 1961, 1(1), p 50-61

15. C.L. Yu, Interfacial Reactions in $\mathrm{Sn} 37 \mathrm{~Pb}, \mathrm{Sn} 3 \mathrm{~Pb} 2 \mathrm{Ag}$ and $\mathrm{Sn} 3.5 \mathrm{Ag}$ BGA Packages, Ph.D. Thesis, Institute of Materials Science and Engineering, National Taiwan University (2001) 